glänzenden Blättchen u. s. w. Auch Anilin löst die Sulfanilsäure auf und bildet damit krystallinische Nadeln, welche wahrscheinlich dem wasserfreien schwefelsauren Ammoniak von Rose entsprechen.

Gerhardt spricht sich hierbei auch gegen die dualistische Theorie aus, nach welcher ebenso wie das Ammonium, beim Anilin ein Anilium, beim Chinin ein Chinium u. s. w. anzunehmen sei, und fügt zur Unterstützung seiner Ansichten noch die folgenden Angaben hinzu. K a $\mathbf{e}$ hat eine Verbindung von Ammoniak mit schwefelsaurem Kupfer analysirt, welche nach Gerhardt's Annahme die Formel $\mathrm{SCu}^{2} \mathrm{O}^{4}, 2 \mathrm{NH}^{3}$ hat; die entsprechende Anilinverbindung wäre $\mathrm{SCu}^{2}, \mathrm{O}^{1}, 2 \mathrm{C}^{6} \mathrm{H}^{7} \mathrm{~N}$. Dieselbe wird mit grosser Leichtigkeit erhalten, wenn man eine verdünnte wässerige Lösung von schwefelsaurem Kupferoxyd mit Anilin und etwas Weingeist versetzt. Es bildet sich ein Niederschlag von pistaciengrinen Tafelchen., Diese neue Verbindung ist kein Doppelsalz, sondern von demselben Typus wie das schwefelsaure Anilin. Man kann das schwefelsaure Kupferanilin auch in ein sulfanolsaures Salz verwandeln, jedoch geschieht diess nur bei einer ziemlich hohen Temperatur. Das sulfanilsaure Ammoniak bildet schöne glänzende, rechtwinklige Tafeln. (Compt. rend. XXI. - Pharm. Centrbl. 1846. No. 19.) B.

\title{
Optisch-aräometrische Bierprobe in ihrer neuesten Vereinfachung.
}

Steinheil hat eine neue Bierprobe ausgemittelt, welche bei angestellten vergleichenden Versuchen gegen die hallymetrische Probe noch genauere Resultate gewahren soll. so dass bei der optisch - aräometrischen Probe der zufällige Beobachtungsfehler $16 \mathrm{mal}$ kleiner ausfält, als bei der hallymetrischen. Zur Anstellung der Proben gehört ein besonderer Apparat, ohne dessen Abbildung auch die Beschreibung nicht gut verständlich wird. Da für unsern Zweck hier die Beschreibung und Abbildung zu weilläufig sein würde, so müssen wir uns begnügen auf dieselbe aufmerksam zu machen und bemerken desshalb, dass sie sich weitläufiger ausgeführt findet im bayerischen Kunst- und Gewerbeblatte 1846. 4-19. - Polylechnischen Centralblatte N.F. IV. S. 117 und daselbsi VII. 9. 387 - 396. B. 